\section{Esterilização cirúrgica voluntária na Região Metropolitana de Campinas, São Paulo, Brasil, antes e após sua regulamentação}

\author{
Voluntary surgical sterilization in Greater \\ Metropolitan Campinas, São Paulo State, Brazil, \\ before and after legal regulation of the procedure
}

\author{
1 Faculdade de Ciências \\ Médicas, Universidade \\ Estadual de Campinas, \\ Campinas, Brasil. \\ 2 Centro de Pesquisas em \\ Saúde Reprodutiva de \\ Campinas, Campinas, Brasil. \\ Correspondência \\ M. J. D. Osis \\ Centro de Pesquisas em \\ Saúde Reprodutiva de \\ Campinas. \\ C. P. 6181, Campinas, SP \\ 13081-970, Brasil. \\ mjosis@cemicamp.org.br
}

\section{Abstract}

This cross-sectional study compared the provision of surgical sterilization in public health services in Greater Metropolitan Campinas, São Paulo State, Brazil, and the characteristics of women and men who underwent sterilization before and after its legal regulation. Structured and pre-tested questionnaires were applied to 398 women, 15 directors of municipal family planning programs, and 15 coordinators of basic health units. Eight municipalities in Greater Metropolitan Campinas provided tubal ligation and nine performed vasectomy. Approximately half reported following the guidelines of the prevailing family planning legislation. There were no significant differences before or after legal regulation in terms of the characteristics of women and men sterilized or the waiting time for surgery. Most tubal ligations were still performed in combination with cesarean sections (the additional payment for sterilization had decreased, but the difference was not significant). There is strong evidence that in Greater Metropolitan Campinas the changes expected from legal regulation of surgical sterilization did not materialize. Although progress has been made, several distortions still need to be corrected.

Reproductive Sterilization; Tubal Sterilization; Vasectomy; Health Public Policy
Luiz Eduardo Campos de Carvalho ${ }^{1}$

Maria José Duarte Osis 2

José Guilherme Cecatti 1,2

Silvana Ferreira Bento 2

Márcia B. Manfrinati 2

\section{Introdução}

A esterilização cirúrgica feminina é o método anticoncepcional mais prevalente no Brasil. Em 1996, entre as mulheres brasileiras em idade reprodutiva que viviam em união, $40 \%$ estavam laqueadas. A prevalência variava de $29 \%$ na Região Sul a 59\% na Região Centro-Oeste 1 . Por outro lado, a vasectomia apresentava ainda baixa prevalência em 1996, mas com sinais de crescimento em relação a pesquisas anteriores. Enquanto em 1986 0,8\% das mulheres unidas referiram que seus companheiros eram vasectomizados 2 , essa proporção alcançou 2,8\% em 19961 .

Sabe-se que a prática da esterilização no Brasil, por muitos anos, aconteceu em um cenário de suposta clandestinidade, já que, ao menos teoricamente, era interpretada como ofensa criminal, com base no Código Penal de 1940, Artigo 29, Parágrafo 2. III, e, segundo o Código de Ética Médica, a realização de esterilização cirúrgica foi proibida até 1988, salvo em algumas situações específicas ${ }^{3}$. Esse contexto de ilegalidade contribuiu para que se verificassem várias distorções na prática da esterilização, como, por exemplo, no caso da laqueadura, a realização de cesariana apenas para encobrir a cobrança adicional, e a sua realização em mulheres muito jovens e com poucos filhos, sob maior risco de arrependimento $3,4,5,6,7,8$.

Foi somente em 1997 que o Ministério da Saúde estabeleceu as regras para a realização da 
esterilização cirúrgica como método anticoncepcional no Sistema Único de Saúde (SUS), através da Portaria $n^{o}$. 144/97 9, que regulamentou os parágrafos correspondentes à esterilização na Lei $n^{\circ}$. 9.263. Desde então, os serviços públicos de saúde devem oferecer, entre outros métodos anticoncepcionais, a laqueadura tubária e a vasectomia, mediante o cumprimento de alguns requisitos. A pessoa solicitante deve ter capacidade civil plena, ser maior de 25 anos ou ter, pelo menos, dois filhos vivos. A cirurgia só pode ser realizada depois de decorridos, no mínimo, sessenta dias a partir da manifestação do desejo de fazê-la; durante esse período a pessoa que solicita a esterilização deverá ser exposta a sessões de orientação, incluindo aconselhamento por equipe multidisciplinar, visando a desencorajar a esterilização precoce. A esterilização não pode ser realizada no momento de um parto ou aborto, exceto quando houver necessidade comprovada, em virtude de cesarianas sucessivas anteriores.

Desde que a realização da esterilização cirúrgica foi regulamentada, houve um grande aumento nos registros de laqueaduras e vasectomias realizadas, o que pode ser constatado através de uma avaliação das autorizações para procedimentos de internação hospitalar, (Autorizações de Internação Hospitalar - AIH). Por exemplo, as laqueaduras registradas nesse sistema passaram de 293, em 1998, para 15.370, em $2001{ }^{3}$. Além disso, não se dispõe de muitas informações sobre como está ocorrendo o atendimento à demanda pela esterilização cirúrgica no SUS.

Na Região Metropolitana de São Paulo, em 1999, foram observados 23 serviços públicos de saúde que ofereciam a esterilização, evidenciando-se uma excelente qualidade técnica, porém uma boa distância entre as normas legais e os serviços oferecidos. Encontraram-se alguns obstáculos ao cumprimento da lei, como, por exemplo, a falta de insumos adequados, clientelismo eleitoral, resistência dos profissionais da saúde em aceitarem os critérios estabelecidos pela lei, especialmente a idade mínima, considerada muito jovem. O principal argumento desses profissionais referia-se à maior possibilidade de arrependimento das pessoas mais jovens 10 .

Outro estudo, realizado por Berquó \& Cavenaghi 3 em seis cidades brasileiras, apontou diferenças de gênero no atendimento da solicitação de laqueadura e vasectomia. Potter et al. 11, que entrevistaram 1.136 mulheres, em três diferentes regiões do Brasil, observaram que a maioria das que, antes do parto, manifestaram o desejo de esterilizar-se não havia mudado de opinião depois de dar à luz. No entanto, em cumprimento à Lei $n^{\circ}$. 9.263, essas mulheres tiveram que espe- rar pelo menos 42 dias depois do parto para serem laqueadas. Os autores ponderaram que isto, embora vise a evitar o arrependimento, também pode resultar em frustração para as mulheres e, muitas vezes, em gravidezes indesejadas.

Em um estudo sobre a oferta de laqueadura na cidade de Ribeirão Preto, São Paulo, verificouse que muitos dos profissionais da saúde envolvidos no atendimento não estavam familiarizados com alguns critérios estabelecidos pela Lei federal de planejamento familiar, como a idade mínima e o número de filhos. Ademais, a pesquisa apontou que ainda se realizava a laqueadura no mesmo momento do parto e, não raramente, durante uma cesariana 12 .

Na Região Metropolitana de Campinas, Estado de São Paulo, estudo realizado antes que a prática da esterilização cirúrgica fosse regulamentada 13 apontou uma prevalência de quase $40 \%$ de laqueadura e de $1 \%$ de vasectomia. Verificou-se que $65,6 \%$ das mulheres laqueadas haviam sido operadas durante uma cesariana, e $53,2 \%$ haviam pago por isto. Mais da metade $(54,2 \%)$ das mulheres havia sido esterilizada antes dos trinta anos de idade, e quase um terço $(32,3 \%)$ tinha, no máximo, dois filhos vivos. No Município de Campinas, em um estudo de coorte retrospectiva com mulheres que haviam tido o primeiro parto em 1985, Cecatti \& Faúndes (O Impacto das Altas Taxas de Cesárea sobre a Fecundidade de uma População: Um Estudo de Coorte Retrospectiva em Campinas, Brasil, 1995. Relatório de pesquisa apresentado à Fundação Ford; 1996) encontraram 26,1\% de laqueadura e pouco mais de $10 \%$ de vasectomia, prevalências semelhantes às observadas por Duarte et al. 14 entre alunos e funcionários de uma universidade na mesma cidade.

Imagina-se que, na vigência da Lei $n^{o}$. 9.263, desde o final de 1997, a situação acima descrita tenha se alterado, porém não se têm notícias de estudos a esse respeito na Região Metropolitana de Campinas. Assim, este artigo tem os seguintes objetivos: comparar características de mulheres e homens residentes na Região Metropolitana de Campinas submetidos à esterilização cirúrgica voluntária antes e após a regulamentação de sua oferta nos serviços públicos de saúde; descrever algumas características do atendimento à demanda pela esterilização nos serviços públicos de saúde da Região Metropolitana de Campinas.

\section{Sujeitos e método}

Neste artigo, é apresentada uma análise secundária de dados de um estudo descritivo que teve como objetivo investigar as condições em que 
estava sendo atendida a solicitação de esterilização cirúrgica voluntária nos serviços públicos de saúde da Região Metropolitana de Campinas, composta por 19 municípios, com uma população de cerca de 2.300.000 habitantes. Para alcançar esse objetivo, desenhou-se um estudo com abordagem quantitativa e qualitativa, com múltiplos sujeitos: mulheres - potenciais usuárias dos serviços públicos de saúde; autoridades de saúde; gestores e provedores do SUS em cada município.

Para o cálculo do tamanho da amostra de mulheres do estudo original, utilizaram-se resultados de Berquó \& Cavenaghi 3 quanto à proporção de usuários que não conseguiram a esterilização pelo SUS, que foi de $49 \%$, com margem de erro (diferença absoluta) e o erro tipo I de $5 \%$, o que resultou em uma amostra de 384 mulheres. Para as análises apresentadas neste artigo, consideraram-se apenas as mulheres laqueadas ( $\mathrm{n}=87$ ) e aquelas que referiram que os maridos ou companheiros eram vasectomizados $(\mathrm{n}=34)$.

A seleção das mulheres foi realizada em ruas previamente sorteadas por meio de uma amostragem sistemática e eqüiprobabilística (probabilidade igual a 196/21.362), com base em um guia 15 que continha todas as ruas dos municípios da Região Metropolitana de Campinas. Foram percorridas 196 ruas, para selecionar, em cada uma delas, mulheres que cumpriam os seguintes critérios de inclusão: idade entre 25 e 45 anos e com pelo menos um filho vivo.

A amostra de mulheres em cada rua sorteada envolveu o percurso a ser seguido pela entrevistadora e a identificação das mulheres elegíveis em cada domicílio selecionado. Cada rua sorteada foi percorrida por uma entrevistadora, inicialmente em ordem crescente do número de domicílios, pelo lado direito da rua. A entrevistadora selecionava, então, o primeiro domicílio da rua, pulava três e selecionava o quarto domicílio, e assim por diante, até conseguir o número determinado de entrevistas: três mulheres por rua. Nos domicílios selecionados, era feito um levantamento das mulheres residentes, para saber se cumpriam os critérios de inclusão. Quando havia mais de uma mulher elegível no domicílio, somente a primeira, pela ordem alfabética, era convidada a participar do estudo. Se, após terminar de percorrer o lado direito da rua, a entrevistadora não tivesse conseguido as três mulheres, ela continuava na mesma rua pelo lado esquerdo, no sentido decrescente da numeração dos domicílios. Quando selecionava e entrevistava as três mulheres, a entrevistadora interrompia o seu percurso naquela rua. Quando completava o percurso, ainda que não tivesse conseguido o número de três entrevistas, ela passava à próxima rua selecionada, uma vez que já havia sido estimada uma porcentagem de perda. Em média, foram entrevistadas duas mulheres por rua percorrida, totalizando 398 entrevistas, realizadas por cinco entrevistadoras especialmente treinadas para isto.

O trabalho de campo ocorreu entre 27 de outubro de 2004 e 02 de fevereiro de 2005, com um intervalo de vinte dias para o recesso de final de ano (de 13 de dezembro de 2004 a 03 de janeiro de 2005). Os dados foram coletados através de um questionário estruturado e pré-testado, com perguntas para caracterizar as participantes, inclusive quanto ao estrato sócio-econômico; para avaliar o conhecimento e uso de métodos contraceptivos, especialmente a esterilização cirúrgica, e a intenção de submeter-se a esta em algum momento. Para as mulheres laqueadas ou cujos companheiros haviam feito vasectomia, perguntou-se sobre o processo de obtenção da esterilização. Na amostra estudada, $68,3 \%$ das mulheres pertenciam aos estratos sócio-econômicos C, D e E, e 27,6\% foram classificadas no estrato B, conforme os critérios da Associação Nacional de Empresas de Pesquisa 16.

Na segunda etapa do estudo, em cada município da Região Metropolitana de Campinas, foram convidados a participar o coordenador municipal da área de saúde da mulher ou de planejamento familiar; o gerente de uma unidade básica de saúde (UBS); os gerentes de ambulatório/centros de referência especializados que foram referidos pelo coordenador municipal como responsáveis pelo atendimento à demanda de esterilização cirúrgica; pessoas responsáveis pelo(s) serviço(s) que realiza(m) as cirurgias (hospitais ou ambulatórios da Região Metropolitana de Campinas). A seleção do gerente de uma UBS se deu através de amostragem aleatória simples a partir da lista de UBSs de cada município, disponibilizada no Cadastro Nacional de Estabelecimento de Saúde. As entrevistas foram realizadas com questionários específicos para cada tipo de gestor/provedor, por telefone ou correio eletrônico.

Os dados coletados foram duplamente digitados, por pessoas distintas; para isso, utilizou-se o programa Sphinx Léxica (Sphinx Brasil, Canoas, Brasil). As duas digitações foram comparadas para identificar e corrigir possíveis erros de digitação, utilizando-se, nesse caso, o programa Epi Info (Centers for Disease Control and Prevention, Atlanta, Estados Unidos), com seu módulo validate. Depois disso, o banco de dados passou por uma análise de consistência lógica. Os problemas identificados foram corrigidos mediante consulta aos questionários preenchidos.

Neste artigo, para a análise dos dados coletados das mulheres, foi calculada a prevalência da esterilização cirúrgica feminina e masculina. 
Em seguida, identificaram-se as mulheres que haviam se submetido, ou cujos companheiros se submeteram, à esterilização em algum município da Região Metropolitana de Campinas, e compararam-se algumas de suas características e do processo seguido para obtenção da esterilização, segundo a data da cirurgia: antes (até 1997) ou depois (a partir de 1998) da regulamentação da lei sobre planejamento familiar. Utilizou-se o teste do qui-quadrado com correção de continuidade ou o teste exato de Fisher para avaliar as diferenças estatísticas entre os grupos de variáveis. O programa utilizado na análise dos dados foi o SPSS versão 11.5 (SPSS Inc., Chicago, Estados Unidos). Para os dados coletados dos gestores e provedores de saúde, prepararam-se tabelas descritivas com as variáveis de interesse.

A participação dos sujeitos foi voluntária. Para as mulheres, o consentimento informado foi obtido oralmente, após o fornecimento das informações relativas à pesquisa e à sua participação. Para os gestores e provedores, o termo de consentimento foi enviado previamente por correio eletrônico ou fax; entendeu-se como seu consentimento o fato de responderem ao questionário e o devolverem por fax ou correio eletrônico, bem como o agendamento e realização da entrevista por telefone. O protocolo da pesquisa foi aprovado pelo Comitê de Ética em Pesquisa da Faculdade de Ciências Médicas da Universidade Estadual de Campinas, que autorizou a dispensa da assinatura do Termo de Consentimento Livre e Esclarecido, nas condições descritas anteriormente.

\section{Resultados}

Dentre as 398 mulheres entrevistadas, $28,4 \%$ estavam laqueadas e $9,5 \%$ referiram que seus companheiros haviam feito vasectomia. Nesse grupo, 87 mulheres e 34 homens haviam se submetido à esterilização cirúrgica em algum dos municípios da Região Metropolitana de Campinas, e 44,8\% das laqueaduras e $44,1 \%$ das vasectomias foram realizadas após a regulamentação da legislação específica sobre esterilização definitiva no Brasil, ou seja, a partir de 1998 (dados não apresentados em tabela).

A maior parte das mulheres esterilizadas nos dois períodos estabelecidos para comparação tinha, no máximo, completado o ensino fundamental, tinha companheiro e se autodeclarou branca. A maioria das mulheres com companheiros vasectomizados tinha escolaridade acima do ensino fundamental, vivia em união e se declarou branca (Tabela 1).

Em relação aos serviços procurados e ao processo seguido para obtenção da laqueadura, tanto antes quanto após a regulamentação legal, a maioria das entrevistadas procurou consultórios particulares e convênios para realização da cirurgia (65\% e 59\%); grande parte das mulheres, mesmo aquelas laqueadas a partir de 1998, referiu não ter passado por equipe multidisciplinar ( $87 \%$ e $81 \%)$, que não lhe foi oferecido outro método anticoncepcional (67\% e $69 \%$ ), mas que lhe foi falado do caráter irreversível da cirurgia (96\% e 82\%). Em relação a esses aspectos, não se observaram diferenças estatísticas ao se com-

Tabela 1

Algumas características das mulheres que foram laqueadas ou cujos maridos se submeteram à vasectomia na Região

Metropolitana de Campinas, São Paulo, Brasil, antes e depois da regulamentação da Lei federal de planejamento familiar.

\begin{tabular}{|c|c|c|c|c|c|c|}
\hline \multirow[t]{2}{*}{ Características } & \multicolumn{2}{|c|}{ Laqueaduras (\%) } & \multirow[t]{2}{*}{$p$ * } & \multicolumn{2}{|c|}{ Vasectomias (\%) } & \multirow[t]{2}{*}{$p$ * } \\
\hline & Até 1997 & $\geq 1998$ & & Até 1997 & $\geq 1998$ & \\
\hline Escolaridade & & & 0,578 & & & 0,882 \\
\hline Até 8a série & 65 & 56 & & 32 & 40 & \\
\hline > 8ạ série & 35 & 44 & & 68 & 60 & \\
\hline Estado marital & & & 0,422 & & & $>0,999$ \\
\hline Sem companheiro & 19 & 10 & & 5 & 0 & $\star \star$ \\
\hline Com companheiro & 81 & 90 & & 95 & 100 & \\
\hline Cor/Raça & & & 0,840 & & & 0,475 \\
\hline Branca & 58 & 54 & & 74 & 60 & $\star \star$ \\
\hline Outra cor & 42 & 46 & & 26 & 40 & \\
\hline $\mathrm{n}$ & 48 & 39 & & 19 & 15 & \\
\hline
\end{tabular}

* Teste qui-quadrado com correção de Yates;

** Teste exato de Fisher. 
pararem as mulheres operadas antes e depois da regulamentação da esterilização; contudo, a porcentagem de laqueadas desde 1998 (24\%) que disse ter assistido a ação educativa em planejamento familiar durante o processo de obtenção da esterilização foi significativamente maior do que a porcentagem de operadas anteriormente (7\%) (Tabela 2).

Em relação ao processo seguido pelos maridos/companheiros que fizeram vasectomia, embora não se tenham observado diferenças estatisticamente significativas, houve maior referência a ter procurado serviços públicos de saúde $-42 \%$ até 1997 e $60 \%$ a partir de 1998; a ter assistido a ação educativa - $26 \%$ e $33 \%$ respectivamente; a lhes ter sido oferecido outro método anticon- cepcional - $20 \%$ e $57 \%$ respectivamente; ter sido falado sobre o caráter irreversível da esterilização - 83\% e 93\% respectivamente. A referência a ter passado por ação educativa foi menor entre os homens que fizeram a cirurgia a partir de 1998 (7\%) do que entre os vasectomizados até 1997 (37\%). Houve diferença significativa quanto a referir que o serviço procurado explicitou critérios de idade e número de filhos, o que ocorreu com $5 \%$ dos vasectomizados antes da regulamentação legal em comparação com $47 \%$ dos que foram operados posteriormente (Tabela 2 ).

Observou-se que, a partir de 1998, cresceu significativamente a proporção de mulheres que foram operadas quando tinham, no mínimo, 25 anos de idade (95\% comparados a $75 \%$ até

\begin{tabular}{|c|c|c|c|c|c|c|}
\hline & \multicolumn{2}{|c|}{ Laqueaduras (\%) } & \multirow[t]{2}{*}{$p$ * } & \multicolumn{2}{|c|}{ Vasectomias (\%) } & \multirow[t]{2}{*}{$p$ * } \\
\hline & Até 1997 & $\geq 1998$ & & Até 1997 & $\geq 1998$ & \\
\hline Tipo de serviço procurado & & & 0,756 & & & 0,490 \\
\hline Público & 35 & 41 & & 42 & 60 & \\
\hline Convênio ou particular & 65 & 59 & & 58 & 40 & \\
\hline \multicolumn{7}{|l|}{ Exigências do serviço } \\
\hline Idade e número de filhos & & & 0,668 & & & 0,011 \\
\hline Sim & 13 & 19 & & 5 & 47 & ** \\
\hline Autorização do(a) companheiro(a) & & & 0,305 & & & $>0,999$ \\
\hline Sim & 22 & 11 & & 5 & 7 & $\star \star$ \\
\hline \multicolumn{7}{|l|}{ Como foi o processo de esterilização } \\
\hline Passou por equipe multidisciplinar & & & 0,668 & & & 0,053 \\
\hline Sim & 13 & 19 & & 37 & 7 & ** \\
\hline Assistiu a ação educativa & & & 0,048 & & & 0,718 \\
\hline Sim & 7 & 24 & & 26 & 33 & ** \\
\hline \multicolumn{7}{|l|}{ Disseram que fariam a laqueadura no parto/ } \\
\hline vasectomia logo depois do parto da mulher & & & 0,924 & & & $>0,999$ \\
\hline Sim & 59 & 62 & & 11 & 7 & ** \\
\hline \multicolumn{7}{|l|}{ Disseram que não podia fazer laqueadura } \\
\hline por ser muito nova & & & 0,250 & & & - \\
\hline Sim & 7 & 0 & ** & - & - & \\
\hline Apenas disseram que fariam a esterilização & & & $>0,999$ & & & - \\
\hline Sim & 7 & 5 & ** & - & - & \\
\hline $\mathrm{n}$ & 46 & 37 & & 19 & 15 & \\
\hline Ofereceram outros métodos anticoncepcionais & & & 0,981 & & & 0,094 \\
\hline Sim & 33 & 31 & & 20 & 57 & \\
\hline $\mathrm{n}$ & 48 & 39 & & 15 & 14 & \\
\hline Falaram do caráter irreversível da esterilização & & & 0,072 & & & 0,607 \\
\hline $\operatorname{Sim}$ & 96 & 82 & $\star \star$ & 83 & 93 & \\
\hline $\mathrm{n}$ & 48 & 39 & & 18 & 15 & \\
\hline
\end{tabular}

* Teste qui-quadrado com correção de Yates;

** Teste exato de Fisher 
1997). Também se verificou diferença significativa entre as médias de idade das mulheres por ocasião da laqueadura, maior entre as operadas a partir de 1998. A grande maioria das laqueaduras continuou sendo realizada no momento do parto e por ocasião de uma cesárea. Embora o pagamento adicional para realizar a laqueadura tenha diminuído desde 1998 (29\% comparados a $50 \%$ até 1997), não houve diferença significativa (Tabela 3).

A maior parte dos homens vasectomizados tinha dois ou mais filhos vivos e teve que esperar no máximo seis meses pela cirurgia. Embora as diferenças não tenham sido estatisticamente significativas, a partir de 1998 foi maior a proporção de homens operados em um serviço público de saúde (60\% comparados a $32 \%$ até 1997$)$ e menor a proporção dos que teriam feito pagamento adi- cional pela cirurgia - $36 \%$ comparados a $63 \%$ até 1997 (Tabela 3).

Quinze dos 19 coordenadores municipais de saúde da mulher ou de planejamento familiar da Região Metropolitana de Campinas responderam ao questionário da pesquisa. Oito referiram que, em seus municípios, são feitas cirurgias de laqueadura e vasectomia, e mais um município relatou que faz a esterilização masculina, mas não a feminina. Desde que a realização da esterilização cirúrgica foi regulamentada, no final de 1997, foram feitas, em média, 682 laqueaduras e 796 vasectomias anualmente no conjunto desses municípios. Apenas dois coordenadores disseram que seus municípios enfrentam dificuldades para atender a demanda por esterilização. Entretanto, o tempo de espera para conseguir fazer as cirurgias foi bastante variado no conjunto de

Tabela 3

Circunstâncias em que ocorreu a esterilização, antes e depois da regulamentação da Lei federal de planejamento familiar.

\begin{tabular}{|c|c|c|c|c|c|c|}
\hline \multirow[t]{2}{*}{ Circunstâncias } & \multicolumn{2}{|c|}{ Laqueaduras (\%) } & \multirow[t]{2}{*}{$p$ * } & \multicolumn{2}{|c|}{ Vasectomias (\%) } & \multirow[t]{2}{*}{$p$ * } \\
\hline & Até 1997 & $\geq 1998$ & & Até 1997 & $\geq 1998$ & \\
\hline \multicolumn{7}{|c|}{ Idade da mulher no momento da esterilização dela/ } \\
\hline do companheiro (anos) & & & 0,027 & & & 0,053 \\
\hline Até 24 & 25 & 5 & & 26 & 0 & $\star \star$ \\
\hline$\geq 25$ & 75 & 95 & & 74 & 100 & \\
\hline Idade média (desvio-padrão) & $27,5(4,2)$ & $32,2(4,7)$ & $<0,001 \star \star \star$ & $28,8(5,8)$ & $32,2(4,3)$ & $0,089 \#$ \\
\hline Número de filhos & & & $>0,999$ & & & $>0,999$ \\
\hline Até 1 & 2 & 3 & ** & 11 & 13 & ** \\
\hline$\geq 2$ & 98 & 97 & & 89 & 87 & \\
\hline Ocasião da esterilização & & & 0,692 & & & - \\
\hline Durante cesárea & 71 & 77 & & - & - & \\
\hline Outra ocasião & 29 & 23 & & - & - & \\
\hline Parto vaginal \#\# & 6 & 3 & & - & - & \\
\hline Tipo de serviço onde foi realizada & & & 0,722 & & & 0,190 \\
\hline Público & 38 & 44 & & 32 & 60 & \\
\hline Convênio/Particular & 62 & 56 & & 68 & 40 & \\
\hline $\mathrm{n}$ & 48 & 39 & & 19 & 15 & \\
\hline Pagamento por fora & & & 0,080 & & & 0,228 \\
\hline Sim & 50 & 29 & & 63 & 36 & \\
\hline $\mathrm{n}$ & & 48 & 38 & & 19 & 14 \\
\hline Tempo de espera para realização & es) \#\#\# & & 0,617 & & & $>0,999$ \\
\hline Até 6 & 37 & 45 & & 79 & 86 & $\star \star$ \\
\hline$>6$ & 63 & 55 & & 21 & 14 & \\
\hline $\mathrm{n}$ & 46 & 38 & & 14 & 14 & \\
\hline
\end{tabular}

* Teste qui-quadrado com correção de Yates;

** Teste exato de Fisher;

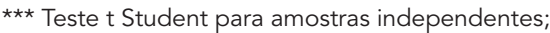

\# Teste não-paramétrico de Mann-Whitney;

\#\# Para fins de análise estatística, considerou-se apenas cesariana versus outra ocasião:

\#\#\# Tempo desde a primeira vez em que foi ao serviço solicitar a esterilização. 
municípios. O menor tempo referido foi de dois meses, para fazer a vasectomia, e o maior foi de 18 meses, no caso da laqueadura (Tabela 4).

Todos os respondentes em cujos municípios se realizava a esterilização cirúrgica declararam existir critérios de idade e número de filhos para atender as solicitações. Quatro deles referiram que esses critérios foram estabelecidos com base na regulamentação legal (Lei $n^{\circ}$. 9.263). Porém, quando os entrevistados explicitaram esses critérios, observou-se que, em dois desses municípios, os critérios de idade e número de filhos não eram exatamente aqueles que constam da lei. Em um deles, por exemplo, a idade para autorizar a laqueadura dependia do número de filhos, de acordo com o hospital em que a cirurgia seria realizada: 25 anos-dois filhos ou 28 anos-três filhos ou 30 anos-dois filhos. Em geral, os coordenadores relataram variações em torno desses critérios de idade e número de filhos e a adição de outros aspectos: que o último filho vivo deva ter no mínimo um ano de idade; que a pessoa esteja há pelo menos cinco anos em união estável; que resida no município há dois anos no mínimo; que as mulheres tenham feito citologia oncótica há seis meses no máximo (dados não apresentados em tabela).

Quinze coordenadores de UBS dos municípios da Região Metropolitana de Campinas responderam ao questionário da pesquisa, e todos afirmaram que as pessoas que chegam à unidade para solicitar a laqueadura são encaminhadas para outros serviços. Em relação à vasectomia, no entanto, um coordenador disse que não tem para onde encaminhar as pessoas que querem se submeter a essa cirurgia. No caso da laqueadura, três unidades encaminham para serviços fora do município, e duas fazem o mesmo em relação à vasectomia. Sete entrevistados declararam que existe um sistema de contra-referência, que permite que a pessoa encaminhada retorne à unidade caso não consiga a esterilização, ou mesmo durante o período de espera para fazer a cirurgia. Apenas três coordenadores disseram que, em suas UBS, as pessoas que querem ser esterilizadas passam por ação educativa antes de serem encaminhadas para outros serviços (Tabela 5).

Treze dos 15 coordenadores de UBS referiram que são seguidos critérios de idade e número de filhos para encaminhar as pessoas para a esterilização cirúrgica. Três entrevistados disseram que os critérios estavam embasados na Lei $n^{\circ}$. 9.263, e quatro apontaram a existência de normatizações municipais (Tabela 5). De forma semelhante ao observado entre os coordenadores municipais, nas UBS os critérios de idade e número de filhos também variavam muito e, mesmo quando se afirmou que estavam baseados na Lei federal de planejamento familiar, observaram-se diversas combinações não previstas nessa Lei, como, por exemplo: 28 anos-dois filhos; 30 anos-três filhos; 35 anos-três filhos (dados não apresentados em tabelas).

Somente três gerentes de UBS afirmaram que não tinham dificuldade alguma para atender a demanda pela esterilização. Seis entrevistados apontaram dificuldades em virtude da falta de infra-estrutura, como a carência de re-

Tabela 4

Algumas características do atendimento à demanda por esterilização cirúrgica na Região Metropolitana de Campinas, São Paulo, Brasil, segundo coordenadores de saúde da mulher/planejamento familiar ( $n=15)$.

\begin{tabular}{lcc}
\hline Características & Laqueadura & Vasectomia \\
\hline Municípios em que as cirurgias são feitas & 8 & 9 \\
Número de cirurgias feitas desde 1998 * & 4.774 & 5.575 \\
Critérios de idade e número de filhos & 8 & 9 \\
Lei federal de planejamento familiar & 4 & 4 \\
Lei federal e protocolo municipal & 1 & 1 \\
Protocolo municipal & 1 & 2 \\
Protocolo de hospital que faz a cirurgia & 2 & 2 \\
Tempo de espera para fazer a cirurgia (meses) ** & $3-18$ & 2 \\
Dificuldades para atender a demanda & 2 & 1 \\
Falta de vagas & 2 & 1 \\
Falta de profissionais treinados & - & \\
\hline
\end{tabular}

* Um município referiu não dispor de registros atualizados;

** Tempo desde a primeira vez em que foi ao serviço solicitar a esterilização. 
Algumas características do atendimento à demanda por esterilização cirúrgica em unidades básicas de saúde (UBS) da Região Metropolitana de Campinas, São Paulo, Brasil, segundo coordenadores/gerentes das unidades $(n=15)$.

\begin{tabular}{|c|c|c|}
\hline & Laqueadura & Vasectomia \\
\hline Encaminhamento para outro serviço & 15 & 14 \\
\hline Dentro do município & 12 & 12 \\
\hline Fora do município & 3 & 2 \\
\hline \multicolumn{3}{|l|}{ Sistema de contra-referência * } \\
\hline Sim & 7 & 7 \\
\hline Não & 4 & 4 \\
\hline Ação educativa antes de encaminhar & 3 & 3 \\
\hline Critérios de idade e número de filhos ** & 13 & 13 \\
\hline Lei federal de planejamento familiar & 3 & 3 \\
\hline Lei/Protocolo municipal & 4 & 4 \\
\hline Outra fonte & 4 & 4 \\
\hline Não sabiam informar & 2 & 2 \\
\hline \multicolumn{3}{|l|}{ Dificuldades para atender a demanda *** } \\
\hline Nenhuma & 3 & 3 \\
\hline Infra-estrutura na UBS (pessoal, espaço) & 6 & 6 \\
\hline Tempo de espera & 4 & 4 \\
\hline Encaminhamento (processo, hospital credenciado) & 3 & 3 \\
\hline
\end{tabular}

* Dois coordenadores não sabiam informar, e dois não responderam

** Os coordenadores de duas UBS não sabiam informar se havia critérios estabelecidos;

*** Cada coordenador podia mencionar mais de uma dificuldade e dois não sabiam informar.

cursos humanos e de espaço físico apropriado para o desenvolvimento das ações em planejamento familiar; quatro enfrentavam problemas relacionados à longa espera para agendamento das consultas nos respectivos ambulatórios de referência; três não conseguiam atender a demanda por não terem hospitais credenciados nem ambulatórios especializados nos próprios municípios (Tabela 5).

\section{Discussão}

Os resultados aqui discutidos não podem ser considerados conclusivos, uma vez que o tamanho da amostra estudada não foi definido originalmente com o objetivo de comparar as características das pessoas esterilizadas antes e depois da regulamentação legal. Todavia, eles permitem pensar que, embora pareça ter havido mudanças, existem fortes indícios de que algumas alterações esperadas com a regulamentação da legislação específica sobre esterilização, tais como diminuição do número de cesarianas, redução do número de laqueaduras realizadas no pós-parto imediato e maior informação sobre os diferentes métodos anticoncepcionais, assim co- mo acesso a estes, não ocorreram da forma como se imaginava.

De maneira geral, os resultados deste estudo sugerem que, na Região Metropolitana de Campinas, a maior parte das características sócioeconômicas e demográficas das mulheres que se submeteram à laqueadura depois de sua regulamentação legal não diferiu das características daquelas que o fizeram anteriormente, assemelhando-se, inclusive, com o que já se observara em estudos anteriores 5,17,18,19,20. O processo seguido para obter a laqueadura, porém, apresentou algumas diferenças que podem indicar efeitos da regulamentação legal. Por outro lado, o perfil dos homens que fizeram vasectomia a partir de 1998, traçado a partir das referências de suas esposas/companheiras, diferiu do daqueles que tinham sido operados antes quanto à escolaridade e a cor da pele, e a análise do processo pelo qual passaram para obter a vasectomia sugere que a regulamentação legal favoreceu o acesso a essa cirurgia nos serviços públicos de saúde, incrementando-se a observância das condições legais estabelecidas.

A proporção de mulheres laqueadas encontrada na amostra estudada $(28,4 \%)$ confirma dados já descritos na literatura 17 , isto é, apesar de 
ser menor que a prevalência nacional observada em 1996, em torno de $40 \%{ }^{1}$, a laqueadura ainda se apresenta como o método anticoncepcional mais prevalente. De forma semelhante, mantendo uma tendência já verificada anteriormente 14 , a porcentagem de homens vasectomizados $(9,5 \%)$ na Região Metropolitana de Campinas foi quase quatro vezes maior que a prevalência nacional (2,6\% segundo a última Pesquisa $\mathrm{Na}$ cional sobre Demografia e Saúde - PNDS/1996) e ligeiramente superior à do Estado de São Paulo $(6,1 \%) 1$.

As características de mulheres e homens que haviam se submetido à esterilização cirúrgica na amostra estudada também são compatíveis com resultados de estudos anteriores na mesma região e no Estado de São Paulo 7,14,18,20,21. Entretanto, quando se compararam as mulheres que se submeteram à laqueadura antes da regulamentação da Lei $^{\circ}$. 9.263 com as que foram operadas posteriormente, verificou-se mudança no que diz respeito à idade no momento da laqueadura. Os resultados evidenciaram que, em geral, foi respeitado o limite inferior de idade previsto pela legislação em vigor, pois apenas 5\% das mulheres que disseram ter feito a laqueadura a partir de 1998 tinham menos de 25 anos nessa ocasião; no grupo submetido à laqueadura antes da regulamentação legal, um quarto das mulheres havia sido esterilizado com menos de 25 anos. A média de idade das mulheres no momento da cirurgia, após 1998, foi significativamente maior do que anteriormente (32 anos, em comparação com 27 anos), ao contrário do que se poderia imaginar, uma vez que a lei permite a esterilização com 25 anos. Resultados semelhantes foram encontrados por Vieira \& Ford 12 em um levantamento feito na cidade de Ribeirão Preto, São Paulo, sobre a oferta de esterilização feminina após a regulamentação, onde a média da idade das mulheres no momento da laqueadura foi de 32,8 anos. Esses achados podem indicar, por um lado, uma melhoria no acesso à contracepção, o que estaria levando as mulheres a postergarem a laqueadura; por outro lado, também se pode pensar que os serviços públicos de saúde não estejam adotando estritamente os critérios legais para a idade a partir da qual se poderia autorizar a laqueadura 3,12 .

A mesma tendência se fez presente em relação ao número de filhos: tanto entre as mulheres operadas antes da regulamentação legal quanto entre as esterilizadas a partir de 1998, a maioria das entrevistadas referiu um número de filhos superior a dois no momento da cirurgia. Logo, existem dois cenários possíveis: em primeiro lugar, um grupo de mulheres atinge um número de filhos maior que o desejado por não conseguir controlar a sua fecundidade, por falta de informação ou de acesso aos diferentes métodos anticoncepcionais, e a laqueadura aparece como a única forma de parar de ter filhos 17; outro possível cenário seria a existência de um grupo mais expressivo de mulheres que conseguem planejar sua fecundidade ao longo da vida reprodutiva, utilizando métodos contraceptivos reversíveis, $\mathrm{e}$ realmente fazem a opção consciente pela laqueadura no momento em que não desejam mais filhos.

Por outro lado, as mudanças no perfil dos homens vasectomizados, detectadas a partir da referência de suas esposas/companheiras, podem sugerir que a regulamentação legal esteja favorecendo um maior acesso de homens de menor escolaridade e não brancos a essa forma de contracepção. Isso foi apontado também em pesquisa recente 22 realizada com homens submetidos à vasectomia nos serviços públicos de saúde de Campinas, o maior município da Região Metropolitana de Campinas.

As características do processo para obtenção ou realização da esterilização, especialmente no caso da laqueadura, foram amplamente discutidas na literatura nacional, evidenciando-se que falta de informação e orientação sobre os diferentes métodos anticoncepcionais, as altas taxas de cesariana (que muitas vezes encobriam a laqueadura) e o pagamento "por fora" eram extremamente comuns antes que entrassem em vigor os parágrafos da Lei $n^{\circ} .9 .263$ referentes à esterilização cirúrgica, ao final de 1997 6,7,8,23. A expectativa, porém, era de que uma nova realidade surgiria após a regulamentação da lei, a qual, além dos critérios relacionados à idade e ao número de filhos, exige que a esterilização seja realizada somente após o casal receber esclarecimentos sobre os diferentes métodos anticoncepcionais, através de orientação de uma equipe multidisciplinar e, no mínimo, sessenta dias após a solicitação. O presente estudo aponta que, na Região Metropolitana de Campinas, mesmo após 1998, pouca coisa se alterou no que diz respeito às características do processo para obtenção e realização da esterilização voluntária, pois grande parte das mulheres entrevistadas, laqueadas ou cujos maridos fizeram vasectomia, continuam procurando serviços privados/convênios, não assistem a palestras nem participam de ações educativas e não passam por uma equipe multidisciplinar. Além disso, nos serviços procurados, pouco se exigiu em relação aos critérios de idade ou número de filhos. Diante disso, Berquó \& Cavenaghi 3 igualmente apontam para a pouca mudança na prática usual da esterilização após a regulamentação da lei. 
Também contrariando as expectativas quanto ao que ocorreria após a regulamentação legal da esterilização, os resultados apontaram a persistência das altas taxas de cesariana no momento da laqueadura, em torno de $80 \%$, e de remuneração "por fora". Tal fato, no passado, foi vinculado ao caráter de ilegalidade da esterilização feminina 3,8 . Uma possível explicação para este achado talvez esteja relacionada ao fato de os programas de planejamento familiar em vários municípios da Região Metropolitana de Campinas terem começado a funcionar de forma efetiva recentemente, de maneira que ainda não houve tempo suficiente para atender a uma demanda reprimida pela esterilização, o mesmo tendo sido observado em outros locais por Berquó \& Cavenaghi 3 , Luiz \& Citeli 10 e Viera \& Ford 12 . Essa situação pode ter levado as mulheres a procurarem os serviços privados e convênios para conseguirem fazer a laqueadura no momento do parto. Nesses tipos de serviços, é notório o predomínio da cesariana como forma de parto, bem como o pagamento "por fora”, o que facilitaria também a realização da laqueadura simultaneamente.

Do ponto de vista da oferta de serviços, os dados aqui levantados, assim como em outros estudos 3,23 , permitiram identificar várias dificuldades para atender a demanda pela esterilização cirúrgica, especialmente a partir das UBS, que referiram falta de infra-estrutura e problemas para viabilizar o encaminhamento das pessoas aos serviços de referência. Isso se reflete no tempo de espera para as duas cirurgias, que abre a possibilidade de gravidezes indesejadas, caso não haja o acompanhamento necessário das pessoas que estão na fila de espera. Uma vez que a Região Metropolitana de Campinas está entre as que, no Brasil, apresentam os melhores indicadores de atenção à saúde, e à luz dos poucos trabalhos já realizados em outras regiões, é possível pensar que os problemas relativos à provisão da esterilização cirúrgica no contexto dos direitos reprodutivos ainda necessitam de medidas concretas para se corrigirem as distorções.

\section{Resumo}

Realizou-se estudo de corte transversal para comparar características do atendimento à demanda pela esterilização cirúrgica voluntária nos serviços públicos de saúde da Região Metropolitana de Campinas, São Paulo, Brasil, e características de mulheres e homens submetidos à esterilização nessa região, antes e após a regulamentação legal. Aplicaram-se questionários estruturados e pré-testados a 398 mulheres, 15 gestores municipais da área de planejamento familiar $e 15$ coordenadores de unidades básicas de saúde. Em oito municípios foi referida a realização da laqueadura, $e$ em nove, a da vasectomia, na metade dos quais se afirmou seguir os critérios estabelecidos pela Lei federal de planejamento familiar. Não se observaram diferenças significativas quanto a características das mulheres e homens esterilizados antes e depois da regulamentação legal, nem quanto ao tempo de espera pela cirurgia. A maior parte das laqueaduras continuou a ser realizada durante uma cesárea; o pagamento "por fora" diminuiu, porém a diferença não foi significativa. Existem fortes indícios de que, na Região Metropolitana de Campinas, as mudanças produzidas com a regulamentação da legislação específica sobre esterilização não ocorreram da forma esperada. Apesar de avanços, ainda existem várias distorções que precisam ser corrigidas.

Esterilização Reprodutiva; Esterilização Tubária; Vasectomia; Políticas Públicas de Saúde

\section{Colaboradores}

L. E. C. Carvalho, M. J. D. Osis, S. F. Bento e M. B. Manfrinati participaram ativamente do desenho do estudo e de todas as suas etapas. J. G. Cecatti participou da análise dos dados. Os três primeiros autores foram responsáveis pela redação da primeira versão do artigo, que foi lida e revisada por todos os autores.

\section{Agradecimentos}

Projeto de pesquisa apoiado pela Fundação de Amparo à Pesquisa do Estado de São Paulo (FAPESP, processo $\left.n^{\circ} .04 / 03811-0\right)$ e pela Organização Mundial da Saúde (OMS, processo A 45099). 


\section{Referências}

1. Sociedade Civil Bem-Estar Familiar no Brasil. Pesquisa Nacional sobre Demografia e Saúde, 1996. Rio de Janeiro: Sociedade Civil Bem-Estar Familiar no Brasil/Programa de Pesquisas de Demografia e Saúde/Macro International Inc.; 1997.

2. Sociedade Civil Bem-Estar Familiar no Brasil/Instituto para Desenvolvimento de Recursos. Pesquisa Nacional sobre Saúde Materno-Infantil e Planejamento Familiar. Brasil: 1986. Rio de Janeiro: Sociedade Civil Bem-Estar Familiar no Brasil; 1987.

3. Berquó E, Cavenaghi S. Direitos reprodutivos de mulheres e homens face à nova legislação sobre esterilização voluntária. Cad Saúde Pública 2003; 19 Suppl 2:S441-53.

4. Hardy E, Bahamondes L, Osis MJD, Costa RG, Faúndes A. Risk factors for tubal ligation, detectable before surgery. Contraception 1996; 54:15962.

5. Pinotti JA, Díaz A, Díaz MM, Hardy E, Faúndes A. Identificação de fatores associados à insatisfação após a esterilização cirúrgica. Ginecologia e Obstetrícia Brasileira 1986; 9:304-9.

6. Potter JE. The persistence of outmoded contraceptive regimens: the case of Mexico and Brazil. Popul Dev Rev 1999; 25:703-39.

7. Vieira EM. A esterilização de mulheres de baixa renda em região metropolitana do sudoeste do Brasil e fatores ligados à sua prevalência. Rev Saúde Pública 1994; 28:440-8.

8. Vieira EM. O arrependimento após esterilização feminina. Cad Saúde Pública 1998; 14 Suppl 1:S5968.

9. Brasil. Portaria $\mathrm{n}^{\circ}$. 144, de 20 de novembro de 1997. Brasília: Diário Oficial da União 1997; 24 nov.

10. Luiz OL, Citeli MT. Esterilização cirúrgica voluntária na Região Metropolitana de São Paulo: organização e oferta de serviços, 1999. http://www. redesaude.org.br/jornal/html/body_jr21-olinda. html (acessado em 12/Nov/2003).

11. Potter JE, Pérpetuo IHO, Berquó E, Hopkins K, Leal OF, Formiga MC, et al. Frustrated demand for postpartum female sterilization in Brazil. Contraception 2003; 67:385-90.

12. Vieira EM, Ford NJ. Provision of female sterilization in Ribeirão Preto, São Paulo, Brazil. Cad Saúde Pública 2004; 20:1201-10.
13. Pinotti JA, Faúndes A, Hardy E, Rebelo-Simões I, Osis MJD, Souza TR, et al. Avaliação da assistência ginecológica no Estado de São Paulo. Rev Bras Ginecol Obstet 1990; 1:7-21.

14. Duarte GA, Alvarenga AT, Osis MJD, Faúndes A, Sousa MH. Participação masculina no uso de métodos contraceptivos. Cad Saúde Pública 2003; 19:207-16.

15. Digicamp Publicações. Guia de ruas da Região Metropolitana de Campinas. Campinas: Digicamp Publicações; 2003.

16. Associação Nacional de Empresas de Pesquisa. Critério de classificação econômica Brasil. http:// www.anep.org.br/codigosguias/CCEB.pdf (acessado em 05/Set/2003).

17. Carvalho LEC, Cecatti JG, Osis MJD, Sousa MH Número ideal de filhos como fator de risco para laqueadura tubária. Cad Saúde Pública 2004; 20:1565-74.

18. Faúndes A, Costa RG, Pádua KS, Perdigão AM. Associação entre prevalência de laqueadura tubária e características sócio-demográficas de mulheres e seus companheiros no Estado de São Paulo, Brasil. Cad Saúde Pública 1998; 14 Suppl 1:S49-57.

19. Hardy E, Osis MJD, Faúndes A, Alves G, Pinotti JA A laqueadura tubária precoce e durante a cesárea. Dimensões atuais e fatores que a determinam. Rev Bras Ginecol Obstet 1993; 4:70-6.

20. Osis MJD, Hardy E, Simões IR, Vera S, Faúndes A. Laqueadura tubária nos serviços de saúde do Estado de São Paulo. Rev Bras Ginecol Obstet 1990; 1:195-204.

21. Vieira EM, Badiani R, Fabbro ALD, Rodrigues Junior AL. Características do uso de métodos anticoncepcionais no Estado de São Paulo. Rev Saúde Pública 2001; 36:263-70.

22. Marchi NM. Conseqüências da vasectomia entre homens submetidos à cirurgia em Campinas, São Paulo [Tese de Doutorado]. São Paulo: Faculdade de Saúde Pública, Universidade de São Paulo; 2006.

23. Minella LS. Aspectos positivos e negativos da esterilização tubária do ponto de vista de mulheres esterilizadas. Cad Saúde Pública 1998; 14 Suppl 1: S69-79.

Recebido em 22/Dez/2005

Versão final reapresentada em 14/Mai/2007 Aprovado em 28/Mai/2007 